data for the Sundh paper were presented as those with a score of 0-3 compared to those with a score $\geq 4$. Using Cox regression analyses the predictive value of the DOSE index was compared to other items. The methodological processes used by both papers were sound. However, for clinical use, a measure that can be used to assess change in status over time is likely to be more helpful than a measure that assesses prognosis only at one particular moment. Stratifying the DOSE at a single cut point will limit its utility in this regard. The possibility that DOSE can be used as a continuous variable, however, is one that needs to be investigated further.

Data recently presented at the 2012 International Primary Care Respiratory Group (IPCRG) World Conference in Edinburgh showed that the DOSE index but not the ADO index was a predictor of future admissions and exacerbations. ${ }^{8}$ When taking mortality as an outcome, the DOSE index has been shown to be a useful predictor of mortality in both primary and secondary care settings, yet not as strongly as the BODE and ADO indices. On the other hand, the BODE index is currently not as useful in a primary care setting where the 6-minute walk test is not routinely available. The ADO index, while simple to perform, is strongly tied to the factor 'age'. The conclusion is that the DOSE index may be the one index to meet all the criteria required of an index for use in routine primary care clinical practice, one which would provide healthcare professionals with a measure of current status and future risk in their COPD patients.

Conflicts of interest The authors declare that they have no conflicts of interest in relation to this article. NHC is an Associate Editor of the PCRJ, but was not involved in the editorial review of, nor the decision to publish, this article.
Commissioned article; not externally peer-reviewed; accepted 16th July 2012 online 26th July 2012

(C) 2012 Primary Care Respiratory Society UK. All rights reserved http://dx.doi.org/10.4104/pcrj.2012.00066

Prim Care Respir J 2012; 21(3): 245-246

\section{References}

1. Postma D, Anzueto A, Calverley $P$, et al. A new perspective on optimal care for patients with COPD. Prim Care Respir J 2011;20(2):205-09. http://dx.doi.org/ 10.4104/pcrj.2011.00041

2. Sundh J, Janson C, Lisspers K, Ställberg B, Montgomery S. The Dyspnoea, Obstruction, Smoking, Exacerbation (DOSE) index is predictive of mortality in COPD. Prim Care Respir J 2012;21:295-301. http://dx.doi.org/10.4104/ pcrj.2012.00054

3. Jones RCM, Donaldson GC, Chavannes $\mathrm{NH}$, et al. Derivation and Validation of a Composite Index of Severity in Chronic Obstructive Pulmonary Disease - The DOSE Index. Am J Resp Crit Care Med 2009;180:1189-95. http://dx.doi.org/10.1164/rccm.200902-02710C

4. Celli BR, Marin JM, Cote CG, Aguirre A, Macario CC. Prognostic assessment of patients with COPD. Lancet 2009;374(9705):1885. http://dx.doi.org/10.1016/ S0140-6736(09)62082-1

5. Oga T, Tsukino M, Hajiro T, Ikeda A, Nishimura K. Predictive properties of different multidimensional staging systems in patients with chronic obstructive pulmonary disease. Int J Chron Obstruct Pulmon Dis 2011;6:521-6. http://dx.doi.org/ 10.2147/COPD.S24420

6. Mannino DM, Buist AS. Global burden of COPD: risk factors, prevalence, and future trends. Lancet 2007;370(9589):765-73.

http://dx.doi.org/10.1016/S0140-6736(07)61380-4

7. Mannino DM, Gagnon RC, Petty TL, Lydick E. Obstructive lung disease and low lung function in adults in the United States: data from the National Health and Nutrition Examination Survey, 1988-1994. Arch Intern Med 2000;160(11):1683-98. http://dx.doi.org/ 10.1001/archinte.160.11.1683

8. Gabe-Thomas E, Jones RCM, Chavannes NH, Lee A, Hyland M, Price D. A comparison of multi-component indices of COPD severity in primary care: an UNLOCK study from the IPCRG Prim Care Respir J 2012:21(2): A7, Abstract number 153.

\title{
Pandemic influenza vaccination for healthcare workers in primary care: good progress, but higher uptake required
}

See linked article by Hothersall et al. on pg 302

\section{*Colin R Simpson}

a Allergy and Respiratory Research Group, Centre for Population Health Sciences, The University of Edinburgh, Edinburgh, UK

b Health Protection Scotland, Glasgow, UK

*Correspondence: Dr Colin Simpson, Allergy \& Respiratory Research Group, Centre for Population Health Sciences, The University of Edinburgh, Doorway 3, Medical School, Teviot Place, Edinburgh, EH8 9AG, UK.

Tel: +44 (0)1316514151 Fax: +44 (0)1316509119

E-mail: c.simpson@ed.ac.uk

There were three global epidemics of influenza in the last century in 1918-19, 1957-58 and 1968-69 - which resulted in considerable morbidity and mortality; the number of deaths in these pandemics has been estimated at 20 to 40 million, 1 million and 1 million, respectively. The lack of herd immunity to the novel influenza viruses implicated (i.e. H1N1, H2N2 and H3N2) is believed to have been a key factor contributing to these very high numbers of deaths. ${ }^{1}$

The World Health Organization (WHO) subsequently declared the influenza A, subtype H1N1 virus (which emerged in Mexico in March 2009) a pandemic in June 2009.2 Production of pandemic H1N1 2009 influenza monovalent vaccines began soon after confirmation of outbreaks in Europe and the USA, and in the autumn of 2009 a worldwide vaccination programme began. The pandemic vaccine was shown to be highly effective. ${ }^{3}$ However, significant global numbers of cases occurred prior to the implementation of the pandemic vaccination programme. Whilst the illness severity was in the main mild, early estimates of mortality attributable to the first pandemic wave revealed an estimated 201,200 respiratory deaths, $80 \%$ of which occurred in people aged under 65. ${ }^{4}$ Such estimates make no allowance for the illness burden seen from the same pandemic virus as it became part of the expected seasonal challenge encountered in the 2010/11 flu season and subsequently. In the UK, the severity of impact in the 2010/11 season was arguably worse, as gauged by the increased number of intensive care unit cases and deaths attributable to the H1N1 virus. ${ }^{5}$ These findings support the argument for the offer of routine influenza vaccination to healthcare workers, largely to reduce the nosocomial transmission of influenza to colleagues and vulnerable patients.

Since 1981, recommendations that healthcare workers be immunised for influenza have been in place in the UK. However, 
uptake rates of seasonal influenza vaccination have remained low, leading to a number of radical solutions being suggested such as mandatory vaccination. ${ }^{6}$ During the early stages of the 2009 H1N1 influenza pandemic, uncertainty over pandemic severity and concerns for the integrity of healthcare systems and national infrastructure prompted the WHO to recommend that healthcare workers be prioritised for rapid immunisation. Internationally, there was wide variation in 2009 pandemic vaccine coverage amongst healthcare workers, ranging from $9 \%$ to $92 \%$.

In this issue of the PCRJ, a study by Hothersall and colleagues set out to determine vaccine uptake and attitudes of primary care healthcare workers to the H1N1 2009 pandemic influenza vaccine in Shropshire Primary Care Trust (PCT). ${ }^{8}$ For healthcare workers willing to be vaccinated, most believed the vaccination would bring personal benefit and benefit to colleagues or patients. They were also more likely to have been vaccinated for seasonal influenza in the past, and were willing to be vaccinated in the future. The key issues for those healthcare staff unwilling to be vaccinated included uncertainty surrounding the safety of the vaccine - in particular, fears over Guillain-Barré syndrome, adjuvants, and thiomersal ${ }^{9}$ - and concern over vaccine effectiveness. Furthermore, there was a lack of awareness amongst these staff of the possible health risk they posed to themselves, their patients and their colleagues, by remaining unvaccinated?

In the UK National Health Service (NHS), front line healthcare workers and social care staff, as well as pregnant women and those with chronic diseases, were the first groups to be offered the vaccine..$^{10}$ For NHS healthcare organisations in England, very good data on vaccine coverage of healthcare workers were captured via the ImmForm web system. ${ }^{11}$ From these data, we know that although coverage rates in 2009/10 increased considerably from the previous year's seasonal vaccination in 2008/9 (from 13.0\% to $40.3 \%)$, there was low uptake found amongst nurses employed by hospitals and community health services (35\% vs. $49 \%$ amongst general practitioners). ${ }^{12}$ There was also wide variation in coverage amongst PCTs (lowest - 17.0\%; highest - 92.0\%). In order to determine what led to higher rates of coverage, qualitative studies using face-to-face and telephone interviews were conducted in organisations achieving over $50 \%$ and under $25 \%$ uptake. From the results, it was determined that on an organisational level, better uptake could be achieved if there was:

- provision of flexible and accessible delivery of vaccine to front line staff

- good leadership, with senior colleagues leading by example (being publicly vaccinated etc.)

- a culture of influenza vaccine promotion in the workplace characterised by strong pro-immunisation messages from staff physicians, supervisors, co-workers and other opinion leaders ${ }^{7}$

- and good planning, governance and project management - e.g. setting up a comprehensive implementation plan well ahead of the flu season and the use of targeted approaches underpinned by good information on uptake. ${ }^{12}$

With strong evidence to suggest that nosocomial infection with influenza leads to more severe disease, in the event of any future influenza pandemic it is imperative that the lessons learnt from the 2009/10 pandemic are implemented to help increase coverage amongst front line staff in order to protect vulnerable patients. Misperceptions regarding vaccine safety - which are attributable, in part, to other vaccine scare stories such as MMR - remain a key barrier to uptake amongst healthcare workers. ${ }^{7}$ Since there is little appetite to adopt mandatory vaccination, ${ }^{13}$ the development of a national vaccination strategy for healthcare staff (and the public) is necessary. Furthermore, education programmes - delivered to those refusing the vaccine, and undergraduates undertaking health professional and clinical degrees - are necessary if myths surrounding vaccines are to be addressed and confidence increased.

Conflicts of interest The authors declare that they have no conflicts of interest in relation to this article.

Commissioned article; not externally peer-reviewed; accepted 7th August 2012; online 10th August 2012

(C) 2012 Primary Care Respiratory Society UK. All rights reserved

http://dx.doi.org/10.4104/pcrj.2012.00081

Prim Care Respir J 2012; 21(3): 246-247

\section{References}

1. Nicholls H. Pandemic influenza: the inside story. PLoS Biol 2006;4:e50 http://dx.doi.org/10.1371/journal.pbio.0040050

2. Chan M. World now at start of 2009 influenza pandemic. June 2009. World Health Organization. www.who.int/mediacentre/news/statements/2009/h1n1_pandemic _phase6_20090611/en/index.html.[Last accessed February 2009]

3. Simpson CR, Ritchie LD, Robertson C, Sheikh A, McMenamin J. Effectiveness of H1N1 vaccine for the prevention of pandemic influenza in Scotland, UK: a retrospective observational cohort study. Lancet Infect Dis 2012; http://dx.doi.org/10.1016/\$1473-3099(12)70133-0

4. Dawood FS, luliano AD, Reed C, et al. Estimated global mortality associated with the first 12 months of 2009 pandemic influenza A H1N1 virus circulation: a modeling study. Lancet Infect Dis 2012; http://dx.doi.org/10.1016/S1473-3099(12)70121-4

5. Mytton OT, Rutter PD, Donaldson L. Influenza A (H1N1)pdm09 in England, 2009 to 2011: a greater burden of severe illness in the year after the pandemic than in the pandemic year. Euro Surveill 2012;17:20139.

6. Nair H, Holmes A, Rudan I, Car J. Influenza vaccination in healthcare professionals BMJ 2012;344:e2217. http://dx.doi.org/10.1136/bmj.e2217

7. Prematunge C, Corace K, McCarthy A, Nair RC, Pugsley R, Garber G. Factors influencing pandemic influenza vaccination of healthcare workers - a systematic review. Vaccine 2012;30:4733-43. http://dx.doi.org/10.1016/j.vaccine.2012.05.018

8. Hothersall EJ, de Bellis-Ayres S, Jordan R. Factors associated with uptake of pandemic influenza vaccine among general practitioners and practice nurses in Shropshire. Prim Care Respir J 2012;21:302-07. http://dx.doi.org/10.4104/pcrj.2012.00056

9. Liang XF, Li L, Liu DW, et al. Safety of Influenza A (H1N1) Vaccine in Postmarketing Surveillance in China. N Engl J Med 2011;364:638-47. http://dx.doi.org/ 10.1056/NEJMoa1008553

10. Donaldson $\amalg$, Rutter PD, Ellis BM, et al. Mortality from pandemic A/H1N1 2009 influenza in England: public health surveillance study. BMJ 2009;339:b5213. http://dx.doi.org/10.1136/bmj.b5213

11. Department of Health - data entry tool for frontline healthcare workers http://www.dh.gov.uk/prod_consum_dh/groups/dh_digitalassets/documents/digitala sset/dh_123783.pdf [Last accessed August 2012].

12. Department of Health. Learning the lessons from the H1N1 vaccination campaign for health care workers. London: Crown Copyright 2010

13. Finch, M. Point: Mandatory influenza vaccinations for all health care workers? Seven reasons to say "no." Clinical Infectious Disease 2007;42:1141-3. http://dx.doi.org/10.1086/501466 